Provided for non-commercial research and education use. Not for reproduction, distribution or commercial use.

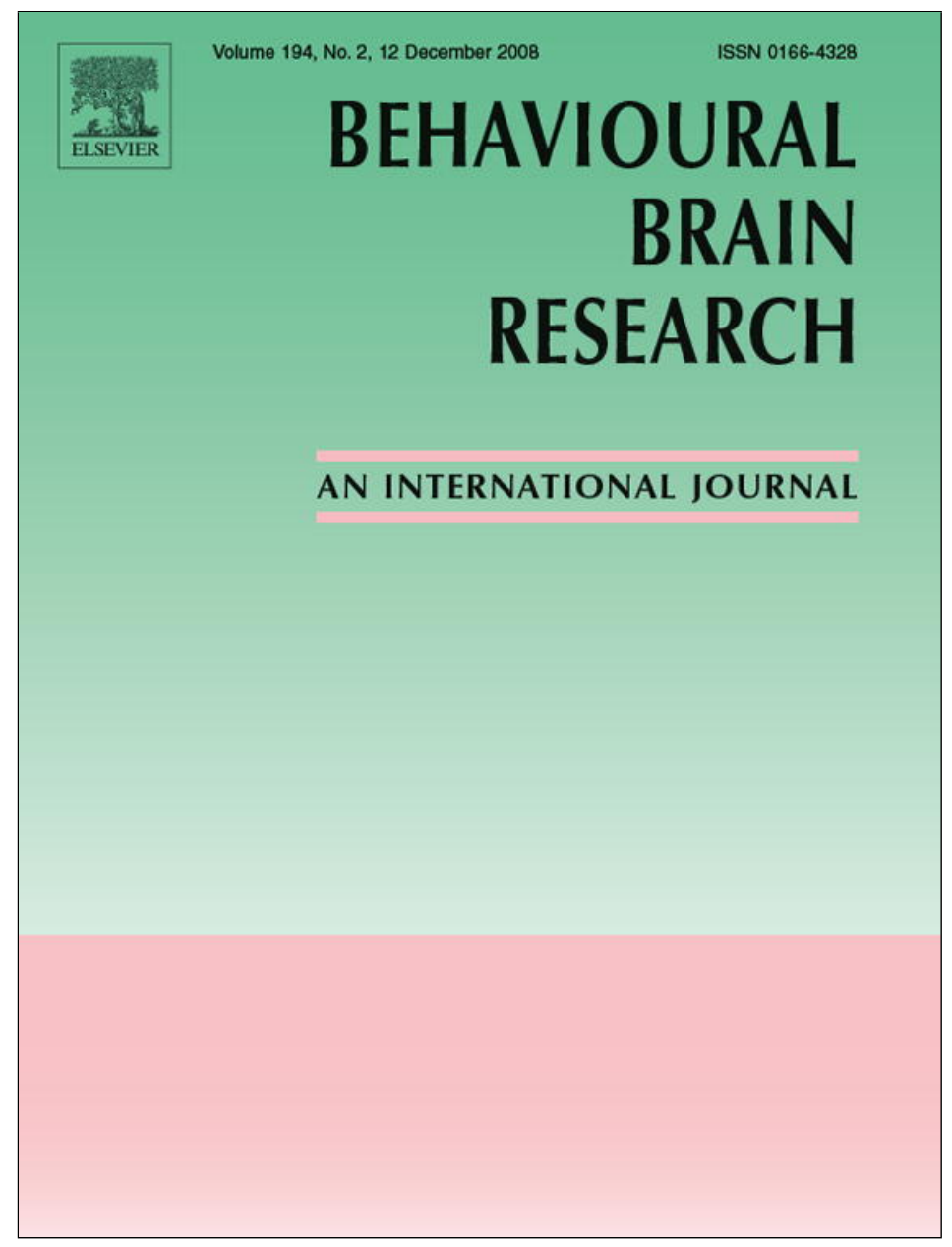

This article appeared in a journal published by Elsevier. The attached copy is furnished to the author for internal non-commercial research and education use, including for instruction at the authors institution and sharing with colleagues.

Other uses, including reproduction and distribution, or selling or licensing copies, or posting to personal, institutional or third party websites are prohibited.

In most cases authors are permitted to post their version of the article (e.g. in Word or Tex form) to their personal website or institutional repository. Authors requiring further information regarding Elsevier's archiving and manuscript policies are encouraged to visit:

http://www.elsevier.com/copyright 
Research report

\title{
Lesions of the entorhinal cortex or fornix disrupt the context-dependence of fear extinction in rats
}

\author{
Jinzhao Ji ${ }^{\mathrm{a}}$, Stephen Maren ${ }^{\mathrm{a}, \mathrm{b}, *}$ \\ a Department of Psychology, University of Michigan, Ann Arbor, MI 48109-1043, United States \\ ${ }^{b}$ Neuroscience Program, University of Michigan, Ann Arbor, MI 48109-0520, United States
}

\section{A R T I C L E I N F O}

\section{Article history:}

Received 3 July 2008

Accepted 10 July 2008

Available online 18 July 2008

\section{Keywords:}

Fear conditioning

Extinction

Entorhinal cortex

Fornix

Freezing

\begin{abstract}
A B S T R A C T
Recent studies have shown that the hippocampus is critical for the context-dependent expression of extinguished fear memories. Here we used Pavlovian fear conditioning in rats to explore whether the entorhinal cortex and fornix, which are the major cortical and subcortical interfaces of the hippocampus, are also involved in the context-dependence of extinction. After pairing an auditory conditional stimulus (CS) with an aversive footshock (unconditional stimulus or US) in one context, rats received an extinction session in which the CS was presented without the US in another context. Conditional fear to the CS was then tested in either the extinction context or a third familiar context; freezing behavior served as the index of fear. Sham-operated rats exhibited little conditional freezing to the CS in the extinction context, but showed a robust renewal of fear when tested outside of the extinction context. In contrast, rats with neurotoxic lesions in the entorhinal cortex or electrolytic lesions in the fornix did not exhibit a renewal of fear when tested outside the extinction context. Impairments in freezing behavior to the auditory CS were not able to account for the observed results, insofar as rats with either entorhinal cortex or fornix lesions exhibited normal freezing behavior during the conditioning session. Thus, contextual memory retrieval requires not only the hippocampus proper, but also its cortical and subcortical interfaces.
\end{abstract}

(c) 2008 Elsevier B.V. All rights reserved.

\section{Introduction}

Considerable work in both humans and animals has implicated the hippocampus in multiple memory processes. Although the precise role of the hippocampus in memory remains hotly debated, many would agree that memories embedded in time and space, including episodic memories in humans, are particularly dependent on the hippocampus. In animals, contextual and spatial learning tasks have been used to model this form of memory; and it is clear that the hippocampus plays a prominent role in these tasks, as well.

Our work over the last several years has employed Pavlovian fear conditioning procedures to study these contextual memory processes in rats. In auditory fear conditioning, an acoustic conditional stimulus (CS) is paired with an aversive footshock (the unconditional stimulus or US) in a novel chamber. After only a single trial (but commonly 3-5 trials), both the auditory CS and the conditioning context (i.e., the chamber) will produce a learned fear

\footnotetext{
* Corresponding author at: Department of Psychology, University of Michigan, 530 Church Street, Ann Arbor, MI 48109-1043, United States. Tel.: +1 734936 6532; fax: +1 7347637480 .

E-mail address: maren@umich.edu (S. Maren).
}

response that is characterized by increases in heart rate and blood pressure, potentiated acoustic startle, and freezing behavior. This conditioned response (CR) can be dampened or "extinguished" by repeatedly presenting the CS in the absence of the US [47]. Interestingly, extinction is highly context-dependent: animals suppress their fear to the CS in the extinction context (which is often different from the conditioning context) but will "renew" their fear to the CS if it is presented in the conditioning context, for example. Hence, extinction does not eliminate fear memories, but rather results in new memories that inhibit fear in the context of extinction [5]. Thus, context can directly signal footshock and produce fear, or it can serve as a retrieval cue to inform the animal when the auditory CS is likely to be followed by footshock, and thereby gate the potential of the CS to yield a fear response. The hippocampus is critical for both types of contextual memory [30].

One brain structure that has been implicated in the contextdependent expression of fear after extinction is the hippocampus [8-10,23,29]; but see refs. [17,54]. For example, rats with electrolytic lesions of the dorsal hippocampus (DH) show impaired context-specific expression of extinction, failing to show a renewal of fear to a CS that is presented outside of the extinction context [29]. In reversible inactivation experiments, muscimol infusions into the $\mathrm{DH}$ prior to testing produce a selective impairment in the context-dependent retrieval of fear extinction, whereas the 
performance of freezing response is not affected [10]. These results suggest the hippocampus is not only an essential component of the brain circuit that permits contextual representations to acquire aversive properties through fear conditioning [16,32,37,46,48], but also helps in using those representations in the service of memory retrieval $[20,26,31]$.

Considering the involvement of the hippocampus in the contextdependence of extinction, it is of interest to determine the role of its major projection systems in the context-specificity of extinction. There are two main projections to the hippocampus: the entorhinal cortex and fimbria/fornix. The entorhinal cortex is the primary cortical interface of the hippocampus, linking the hippocampus with nearly all other association cortices $[1,6,33]$. The fornix is the primary subcortical interface of hippocampus, connecting the hippocampus with other subcortical structures [1,52] and providing the main cholinergic input to the hippocampus from the septum [52]. Substantial work indicates an important role for both the entorhinal cortex and fornix in learning and memory, including contextual and spatial learning $[4,34,38,51]$. However, the role of these structures in context-dependent expression of extinction has received little attention. One report has explored the consequence of fornix lesions on the context-specificity of extinction using barpress suppression to index fear [54], and found modest deficits in fear renewal. The role of the entorhinal cortex in the renewal of fear after extinction is unknown. In the present study, we used Pavlovian fear conditioning in rats to examine the effects of entorhinal cortex or fornix lesions on the context-specificity of extinction. We expected that damage to either structure would interfere with the context-specificity of extinction, an outcome that would be similar to that induced by a hippocampal lesion.

\section{Materials and methods}

\subsection{Subjects}

Subjects were 96 adult male Long-Evans rats (200-224 g) obtained from a commercial supplier (Harlan Sprague Dawley, Indianapolis, IN). After arrival, the rats were housed individually in stainless-steel hanging cages on a $14: 10 \mathrm{~h}$ light/dark cycle (lights on at 7:00 a.m.) and were allowed unlimited access to food and water After being housed, the rats were handled (10-20 s per rat per day) for 5 days to habituate them to the experimenter. All experimental procedures were conducted in accordance with the NIH-approved guidelines as stated by the University of Michigan Committee on Use and Care of Animals (UCUCA).

\subsection{Surgery}

Prior to behavioral testing, rats were treated with atropine methyl nitrate $(0.3 \mathrm{mg} / \mathrm{kg}$, i.p.), anesthetized with sodium pentobarbital (Nembutal; $65 \mathrm{mg} / \mathrm{kg}$, i.p.) and mounted in a stereotaxic apparatus (Kopf Instruments, Tujunga, CA). The scalp was incised and retracted, and the head was positioned to place bregma and lambda in the same horizontal plane. Small burr holes (2-mm diameter) were drilled bilaterally in the skull for the placement of either $28-G$ cannulae in the entorhinal cortex $(n=32)$ or a stainless-steel electrode in the fornix $(n=32)$. Other rats received sham surgery $(n=32)$ for which the scalp was incised and burr holes drilled, but no implantations were made in the brain. For neurotoxic EC lesions, small burr holes (2-mm diameter) were drilled bilaterally in the skull for the placement of a $28-G$ cannulae: (a) $6.8 \mathrm{~mm}$ posterior to bregma, $5.0 \mathrm{~mm}$ lateral to bregma, and $5.0 \mathrm{~mm}$ ventral to dura; and (b) $8.0 \mathrm{~mm}$ posterior to bregma, $5.0 \mathrm{~mm}$ lateral to bregma, and $5.0 \mathrm{~mm}$ ventral from dura. A $10-\mu$ l Hamilton syringe was mounted in an infusion pump (Harvard Apparatus, South Natick, MA) and connected to injection cannula with polyethylene tubing; NMDA ( $20 \mu \mathrm{g} / \mu \mathrm{l}, 0.4 \mu \mathrm{l} / \mathrm{site}, 0.1 \mu \mathrm{l} / \mathrm{min}$; Sigma, St. Louis, MO) in $100 \mathrm{mM}$ phosphate buffered saline (PBS, pH 7.4) was slowly infused. Electrolytic lesions of the FX were made with constant anodal current $(3.0 \mathrm{~mA}$ for $5 \mathrm{~s})$, which was passed through a stainless-steel electrode insulated with Epoxylite except for an exposed tip $(0.5 \mathrm{~mm})$ [38]. The coordinates for FX lesions were: (a) $1.3 \mathrm{~mm}$ posterior to bregma, $0.5 \mathrm{~mm}$ lateral to bregma, and $3.6 \mathrm{~mm}$ ventral to dura; (b) $1.3 \mathrm{~mm}$ posterior to bregma, $1.2 \mathrm{~mm}$ lateral to bregma, $3.8 \mathrm{~mm}$ ventral to dura. One week of recovery was allowed before behavioral testing.

\subsection{Behavioral apparatus}

Eight identical observation chambers $(30 \mathrm{~cm} \times 24 \mathrm{~cm} \times 21 \mathrm{~cm}$; MED-Associates, St. Albans, VT) were used in all experiments. The chambers were constructed from aluminum (side walls) and Plexiglas (rear wall, ceiling, and hinged front door) and were situated in sound-attenuating cabinets located in a brightly lit and isolated room. The floor of each chamber consisted of 19 stainless-steel rods ( $4 \mathrm{~mm}$ in diameter) spaced $1.5 \mathrm{~cm}$ apart (center-to-center). Rods were wired to a shock source and solid-state grid scrambler (MED-Associates) for the delivery of footshock USs. A speaker mounted outside a grating in one wall of the chamber was used for the delivery of acoustic CSs. Closed-circuit video cameras mounted above each chamber were used to videotape the behavior of each rat and allow observation of the animals from outside of the test rooms.

Features of the chambers were adjusted to generate three distinct contexts. For the first context, the sole source of illumination was overhead fluorescent lighting in the room. The ventilation fans in the sound-attenuating cabinets were turned off, the cabinet doors remained open, and the chambers were cleaned with a $70 \%$ ethanol solution. To provide a distinct odor, stainless-steel pans containing a thin film of the ethanol solution were placed in the chambers. Rats were transported to this context in either white or black plastic boxes (the color of the boxes was randomized across sessions). For the second context, a pair of $40 \mathrm{~W}$ red lights provided illumination (the room lights were turned off). Additionally, the doors on the sound-attenuating cabinets were closed, the ventilation fans were turned off and the chambers were cleaned with a $1 \%$ ammonium hydroxide solution. To provide a distinct odor, stainless-steel pans containing a thin film of this solution were placed underneath the grid floors before the rats were placed inside. Rats were transported to this context in black plastic boxes. For the third context, illumination was provided by the fluorescent room lights and a $15 \mathrm{~W}$ houselight in each chamber. The chambers were cleaned with a $2 \%$ acetic acid solution, the cabinet doors remained open, and stainless-steel pans containing a thin film of the same solution were placed underneath the grid floors to provide a distinct odor before the rats were placed inside. Ventilation fans in each cabinet supplied background noise ( $65 \mathrm{~dB}, \mathrm{~A}$ scale). Rats were transported to this context in white plastic boxes.

\subsection{Procedure}

All rats were submitted to 3 days of behavioral testing: fear conditioning, extinction, and renewal testing. These phases of training were conducted in different experimental contexts. Fear conditioning was conducted in context A, whereas extinction and renewal testing were conducted in contexts $\mathrm{B}$ and $\mathrm{C}$. The actual contexts in which the experimental phases occurred were counterbalanced across groups. For fear conditioning, rats were transported in squads of eight and placed in the conditioning chambers; chamber position was counterbalanced for each squad. The rats received five tone $(10 \mathrm{~s} ; 80 \mathrm{~dB} ; 2 \mathrm{kHz})$-footshock $(1 \mathrm{~s} ; 1 \mathrm{~mA})$ trials $(70 \mathrm{~s}$ intertrial interval) beginning $3 \mathrm{~min}$ after being placed in context A. Sixty seconds after the final shock, the rats were returned to their home cages.

The extinction phase began $24 \mathrm{~h}$ after the conditioning session and consisted of two sessions. For the first session, rats were transported to a novel context (context C) where they remained for $55.5 \mathrm{~min}$ without the presentation of any stimuli. This "exposure" session served to equate the time spent by the rats in both the B and C contexts prior to the renewal test, thereby insuring that rats were familiar with the testing contexts the following day. Approximately $2 \mathrm{~h}$ after the exposure session, the rats were transported to context $\mathrm{B}$ for a 55.5-min extinction session. For extinction training, the rats were presented with 45 tone presentations $(10 \mathrm{~s} ; 80 \mathrm{~dB} ; 2 \mathrm{kHz} ; 60 \mathrm{~s}$ ISI) without the footshock US; the extinction trials commenced 3 min after the rats were placed in the chambers.

Seven days after extinction all rats underwent renewal testing. We used a long interval in between extinction and renewal testing to mirror the procedures in our previous work examining the influence of hippocampal lesions on renewal [29] Testing consisted of a continuous presentation of the auditory CS for $8 \mathrm{~min}(80 \mathrm{~dB}$; $2 \mathrm{kHz}$ ) in either the extinction context (context B) or another context (context C) Hence, half of the rats were tested in the extinction context (ABB, where each letter denotes the context of conditioning, extinction, and testing), whereas the others were tested outside the extinction context $(A B C)$. We refer to these as the SAME and DIFF conditions, respectively. The squads were counterbalanced for both lesion and test context.

We assessed fear to the tone CS by measuring freezing behavior as described previously [36]. Freezing was quantified by computing the number of observations for each rat that had a value less than the freezing threshold (a load cell value below which animals are observed to be freezing) [36]. To avoid counting momentary inactivity as freezing, we only scored an observation as freezing if it fell within continuous group of at least five observations that were all less than the freezing threshold. Thus, freezing was only scored if the rat was immobile for at least $1 \mathrm{~s}$. For each session, the freezing observations were transformed to a percentage of total observations.

\subsection{Histology}

Histological verification of the lesions was performed after behavioral testing Rats were perfused across the heart with physiological saline followed by a $10 \%$ formalin solution. After extraction from the skull, brains were post-fixed in $10 \%$ formalin solution for 2 days, at which time the solution was replaced with a $10 \%$ formalin/30\% sucrose solution until sectioning. Sections ( $50 \mu \mathrm{m}$ thick) were cut 
on a cryostat $\left(-19^{\circ} \mathrm{C}\right)$, wet-mounted on microscope slides, and stained with $0.25 \%$ thionin for visualization of the lesions.

\subsection{Data analysis}

After histological examination, 76 rats were included in the final data analysis (SH $(n=25)$, FX $(n=27)$, EC $(n=24))$. For each session, the freezing data were transformed to a percentage of the total observations, a probability estimate that is amenable to analysis with parametric statistics. These probability estimates of freezing were analyzed using ANOVA (with variables of lesion, trial or block, and test context as appropriate). Post hoc comparisons in the form of Fisher's PLSD tests were performed after a significant omnibus $F$-ratio. All data are represented as means \pm SEMs

\section{Results}

\subsection{Histology}

Fig. 1 shows photomicrographs of coronal brain sections from representative rats with either a neurotoxic EC lesion or an electrolytic FX lesion. Infusions of NMDA into the EC produced substantial cell loss in both the medial and lateral EC, but spared fibers in EC. There was some invasion of the lesion into the ventral subiculum and ventral dentate gyrus, but this was minimal. Typically, the lesions did not involve damage to any of the hippocampal subfields. Electrolytic lesions of FX were associated with damage to the overlying neocortex and the rostral pole of the dorsal hippocampus and septal nuclei in some rats. In both cases the lesions were similar in extent to those reported in previous publications [38,39].

\subsection{Behavior}

Conditional freezing in rats with EC or FX lesions during the conditioning, exposure, extinction, and test sessions is shown in Fig. 2. On the conditioning day (Fig. 2A), immediate post-shock freezing increased significantly across the five conditioning trials (trial: $\left.F_{(10,365)}=194, p<.0001\right)$ and this did not differ among the groups. This replicates our earlier observation that electrolytic EC lesions do not affect freezing during the 60 -s post-shock periods during auditory fear conditioning [39]. However, electrolytic lesions of the entorhinal cortex or fornix reduce immediate post-shock freezing when training consists of unsignaled shocks (i.e., contextual fear conditioning) [38]. Hence, the present results reveal that signaling footshock with an auditory CS limits the influence of fornix or entorhinal cortex lesions on immediate post-shock freezing, which is not surprising given the involvement of other neural systems in the acquisition of fear to auditory CSs.

Twenty-four hours after fear conditioning, the rats were given an exposure session in which they were placed in a novel context to equate their exposure to all the contexts used in the behavioral procedures. As shown in Fig. 2B, freezing in this context was relatively low, but rats did show some generalized fear to the novel context early in the session that dissipated later in the session (block: $F_{(9,657)}=8.9, p<.0001$ ). Interestingly, there were differences in the degree to which rats with entorhinal cortex or fornix lesions generalized fear to the novel context (lesion $\times$ block: $F_{(18,657)}=4.6$, $p<.0001$ ). Post hoc comparisons revealed that rats with entorhinal cortex lesions exhibited significantly less generalized freezing than either sham rats or rats with fornix lesions. This deficit in generalized fear in rats with entorhinal cortex lesions is not surprising insofar as deficits in freezing to a shock-associated context have been reported after either auditory [34,39] or contextual [38] fear conditioning in rats with entorhinal cortex lesions (but see refs. $[3,49])$. It is somewhat surprising, however, that rats with fornix lesions generalized contextual fear normally, insofar as they have been reported to have deficits in contextual freezing after either auditory or contextual fear conditioning $[38,49]$. A recent study, however, suggests that contextual discrimination (and thereby generalization) after fear conditioning is relatively normal in rats with fornix lesions [2], a finding that is consistent with the normal generalized fear we have observed here.

Two hours after the exposure session, all rats were placed in another novel context for an extinction session that consisted of 45 CS-alone presentations. As shown in Fig. 2C, delivery of the CS produced robust freezing in all of the groups early in the extinction session, and this CS-elicited freezing decreased in frequency during the course of the session (block: $F_{(15,1095)}=23.9, p<.0001$ ). Interestingly, entorhinal cortex or fornix lesions produced a mild, but significant, deficit in CS-elicited freezing early in the extinction session (lesion $\times$ block: $\left.F_{(30,1095)}=2.0, p<.005\right)$. This deficit does not appear to be due to difficulty with the performance of freezing behavior, because it normalized late in the extinction session in both of the lesion groups and was not present during the conditioning session in either group (Fig. 2A).

One week after extinction training, the rats were returned to either the context in which they had received extinction train-
(A)
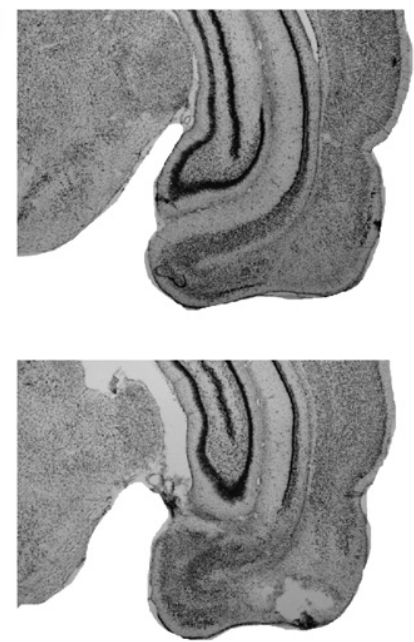
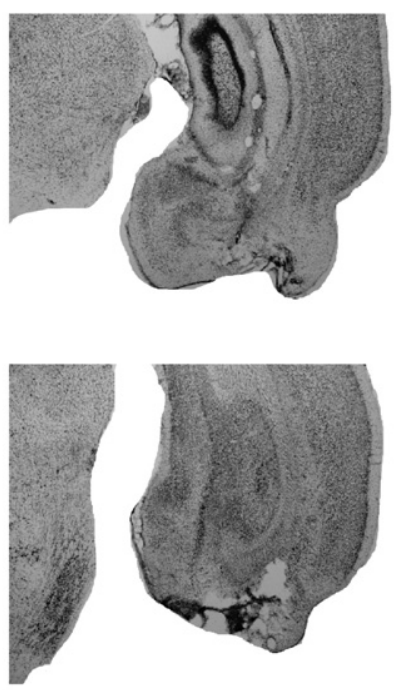

(B)

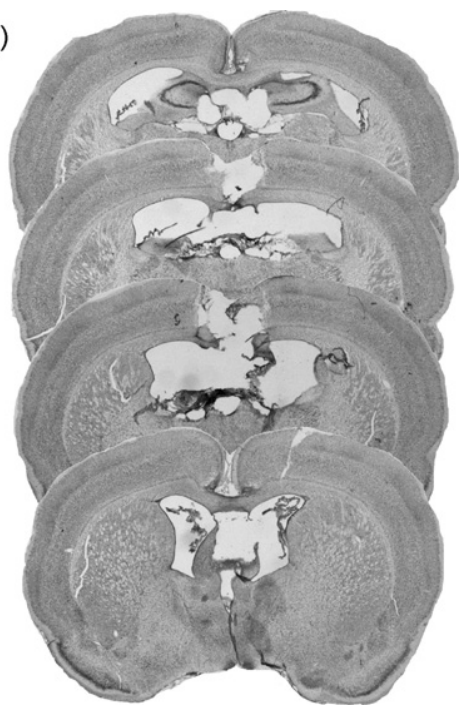

Fig. 1. Photomicrographs showing thionin-stained coronal sections from a representative rat with (A) a neurotoxic lesion of the entorhinal cortex and (B) an electrolytic lesions of the fornix. 
(A) Conditioning (Day 1)

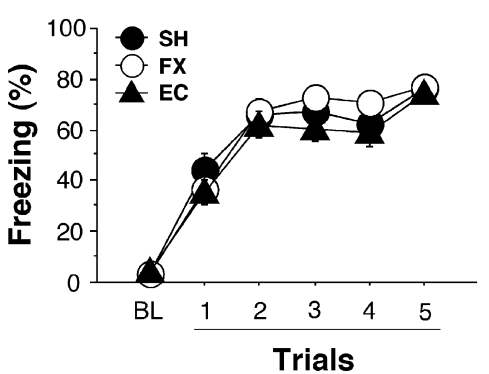

(B) Exposure (Day 2)

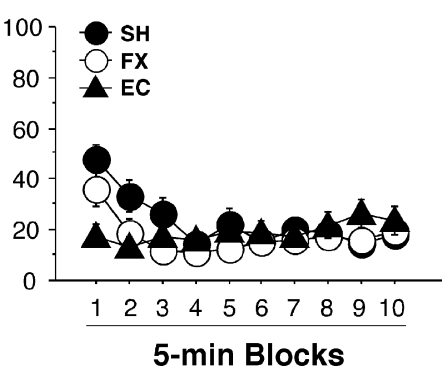

(C) Extinction (Day 2)

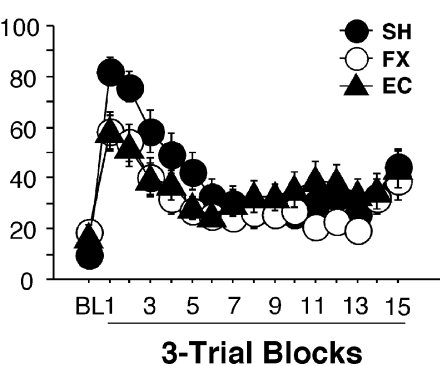

(D) Renewal Test (Day 3)

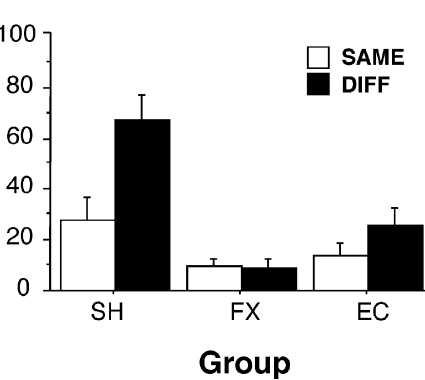

Fig. 2. Effects of entorhinal cortex or fornix lesions on the acquisition, extinction, and renewal of auditory fear conditioning. (A) Percentage of freezing behavior on the conditioning day. Data are averages for the 3-min baseline (BL) and for 1-min periods after each of the five tone-shock conditioning trials. (B) Percentage of freezing behavior during the exposure session prior to extinction. (C) Percentage of freezing during the 45-trial extinction session. Data are averages of the 2-min baseline (BL) followed by averages of the 1-min post-CS intervals collapsed across 5-trial blocks. (D) Percentage of freezing behavior during the renewal test session. Data are averages of freezing during the entire 8-min tone CS for rats tested in either the extinction context (SAME) or a different context from extinction (DIFF). All data are presented as means \pm SEM. EC, entorhinal cortex lesion; FX, fornix lesion; SH, sham surgery.

Extinction

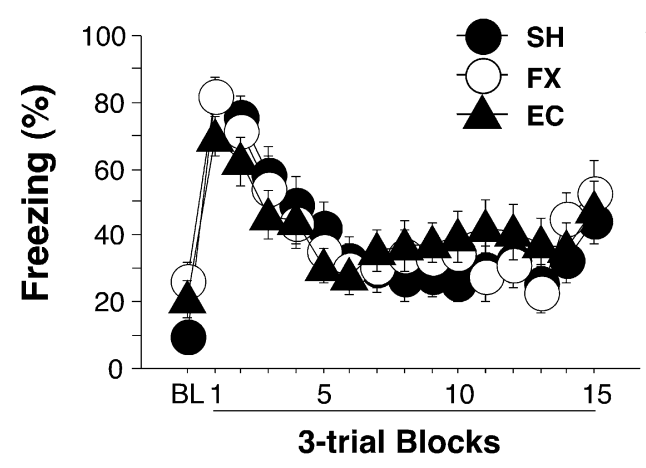

Renewal Test

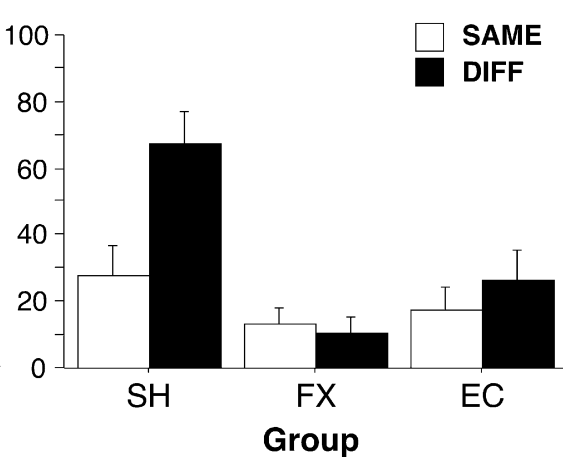

Fig. 3. Effects of entorhinal cortex or fornix lesions on the extinction and renewal of auditory fear conditioning. Only rats in the fornix and entorhinal groups that froze at least $25 \%$ to the CS in the first extinction block were included in the analysis. The data are displayed in the same manner as in Fig. 2.

ing (SAME condition) or to the other "exposure" context (DIFF condition) for the critical renewal test. Fig. 2D shows conditional freezing in all of the groups in each of the test contexts; the data are averaged across the 8-min CS that was used to assess conditional fear in this session. Consistent with many published reports, sham rats exhibited higher conditional freezing when they were presented with the CS outside relative to inside the extinction context. In other words, these rats exhibited a renewal of fear when the CS was encountered in a place that was different from where it had undergone extinction training. In contrast, rats with lesions in either the fornix or entorhinal cortex failed to exhibit an increase in conditional freezing outside of the extinction context (lesion $\times$ context: $\left.F_{(2,70)}=4.6, p<.02\right)$. Moreover, rats with entorhinal cortex or fornix lesions exhibited significantly less freezing than sham rats when the data were averaged across both test contexts (lesion: $F_{(2,70)}=17.4, p<.0001$ ), which may have been a consequence of the robust renewal in the sham rats.

The failure of rats with fornix or entorhinal cortex lesions to renew their fear to an extinguished CS may have been a manifestation of their deficit in freezing to an auditory CS that was evident during the extinction session. To address this possibility, we excluded from the statistical analysis rats with fornix $(n=9)$ or entorhinal cortical lesions $(n=5)$ that exhibited less than $25 \%$ freezing to the auditory CS during the first 5-min block of the extinction session; this left 18 subjects in the fornix group (SAME, $n=8$; DIFF, $n=10$ ) and 19 subjects in the entorhinal cortex group (SAME, $n=9$; DIFF, $n=10$ ). As shown in Fig. 3 , an analysis of this subset of rats revealed no differences relative to controls in freezing to the CS during the extinction session (lesion $\times$ block, $F_{(30,885)}=1.3$ ). Nonetheless, rats with fornix or entorhinal cortex lesions continued to exhibit a robust deficit in renewal of fear to the CS during the renewal test (lesion $\times$ context: $F_{(2,56)}=3.9, p<.03$ ), despite exhibiting normal levels of fear to the CS during the extinction session. Together, these data indicate that rats with entorhinal cortex or fornix lesions exhibited a severe deficit in the context-dependent expression of extinction.

\section{Discussion}

The deficits in the context-dependent expression of extinction in rats with entorhinal cortex or fornix lesions parallels the deficits we have previously observed in rats with large electrolytic lesions of the dorsal hippocampus [29] or more selective neurotoxic lesions of hippocampal areas CA1 or CA3 [28]. These deficits are also similar to those produced by reversible inactivation of the dorsal [8-10] and ventral hippocampus [24]. Thus, across several reports there is a consistent and remarkable involvement of many structures in the hippocampal formation and related cortices in the contextdependent expression of extinction. It should be noted that Bouton and co-workers [54] have observed minimal effects of fornix or hippocampal lesions on the renewal of fear after extinction using bar-press suppression to index fear. As we have previously reported, these differences are not due to differences in renewal designs or the timing or types of lesions [29]. One possibility is that the con- 
ditional freezing is more sensitive to hippocampal damage than bar-press suppression.

In these experiments and previously published work [9,10,29], we have consistently observed that dysfunction in the hippocampal system renders animals that broadly generalize extinction memories (memories that the CS is safe) to contexts that would otherwise renew fear to the CS. We have previously reported that lesions or inactivation of the ventral hippocampus, which have often included the ventral subiculum and entorhinal cortex, produce impairments in the acquisition and expression of auditory fear conditioning [41]. It is therefore possible that the extension of the entorhinal cortex lesions into the ventral subiculum accounts for the deficits in freezing to the auditory CS that we have observed. Similarly, dorsal hippocampal lesions have been reported to disrupt auditory fear under some conditions [37], and lesions of the entorhinal cortex and fornix increase locomotor activity [38]. However, deficits in CS freezing associated with lesions to the fornix or entorhinal cortex do not appear to account for the failure of rats with such lesions to renew their fear to a CS after extinction. For example, although rats with fornix or entorhinal cortex lesions exhibited deficits in conditional freezing to the auditory CS during extinction, they were nonetheless able to support high levels of freezing (approximately 60\%). Furthermore, excluding animals with particularly robust deficits in CS freezing, which equated CS freezing during extinction with controls, did not influence the magnitude of the renewal deficit. Thus, deficits in fear renewal appear to be due to an inability to use contextual cues to guide performance to the CS after extinction $[30,40]$.

What might account for the deficits in the context-dependent expression of fear after extinction in rats with entorhinal cortex and fornix lesions? One possibility is that rats with such lesions are unable to discriminate the exposure context (in which no tone trials were delivered) from the extinction context. Although we did not directly assess context discrimination in these animals, we have previously reported that neither dorsal hippocampal lesions [29] nor inactivation [25] disrupt contextual discrimination. Hence, it is unlikely that the failure of rats with fornix or entorhinal cortex lesions to show renewal is due to a failure to appreciate the context in which the CS is presented. Moreover, any deficits in contextual fear conditioning that may have been present in rats with fornix or entorhinal cortex lesions (e.g., [38]) are not likely to account for the deficit in renewal, insofar as testing occurred in contexts that were not associated with shock at any phase in training. Rats with EC and FX lesions also exhibit substantial (albeit somewhat deficient) freezing to an auditory CS, suggesting that deficits in fear to the CS itself are an unlikely explanation for deficits in renewal of extinguished fear.

We have previously argued that the deficit in the renewal of fear in rats with hippocampal damage is due to an inability to use contextual cues to govern retrieval of the CS memory [30,40]. By this account, performance to the auditory CS in rats with hippocampal system damage is solely determined by its history of reinforcement and is independent of the context in which that reinforcement (or non-reinforcement) occurs. That is, performance is governed by the total associative strength acquired by the CS. Because rats that have undergone extinction training receive many more extinction trials than acquisition trials, associative strength to the CS is low and animals with hippocampal damage therefore exhibit little fear to the CS in any context in which it is encountered. In contrast, intact rats index gains and losses of associative strength to the context in which conditioning and extinction occur, respectively, which thereby permits them to regulate conditional responding to the CS according to the context in which the CS is presented.

The important role of the entorhinal cortex in contextual memory retrieval is not surprising in the light of the substantial anatomical connectivity of this structure with the hippocampus $[18,21,50]$. Moreover, considerable evidence indicates that entorhinal cortex lesions interfere with tasks that require contextual processing $[34,38,53]$. Moreover, recent computational models have suggested specific mechanisms whereby physiological properties of entorhinal cortical neurons might mediate memory retrieval by the hippocampus [22,27,55]. For instance, Hasselmo and Eichenbaum [22] have proposed a model suggesting that sustained activity in layer II neurons of the entorhinal cortex influences hippocampal synaptic modification to provide a temporal context, allowing selective retrieval of specific recent episodes despite variable delays and interference from other recent episodes. In this model, the entorhinal cortex provides the driving force for associative retrieval of sequences.

Not surprisingly, disrupting the major subcortical connections of the hippocampus also impaired fear renewal in the present study. These results are congruent with previous reports suggesting a critical role of the fornix in episodic memory [13]. For example, FX lesions disrupt rats' object location memory, in that they fail to discriminate the object between a familiar and a novel location [14,15]. Learning about configurations of spatial features is impaired after fornix transection [7] and fornix transection in monkeys leads to a severe deficits in learning spatial arrangement of different stimulus objects in different scenes [19]. Also, both rodents and nonhuman primates with fornix lesions exhibit a severe impairment in a spatial delayed nonmatching-to-sample $[43,44]$. Importantly, rats with fornix lesions demonstrate impaired memory for the contextspecificity in which an object has previously been found $[12,45]$.

The present results reveal that both the cortical and subcortical interfaces of the hippocampus are essential in the contextdependence of extinction. Indeed, these data indicate that the entorhinal cortex and fornix are involved in both contextual memory encoding and retrieval. Together with previous studies $[8-10,23,29]$, the current work bolsters the important role of the hippocampal system in the contextual modulation of fear memory after extinction. Future work is required to elucidate how the hippocampus interacts with cortical and subcortical afferents in the contextual regulation of fear extinction. Interactions of the hippocampus with the prefrontal cortex (via the fornix) and amygdala (via the ventral subiculum and entorhinal cortex) are likely to play an important role in the contextual control of fear after extinction $[11,35,42]$.

\section{Acknowledgements}

This research was supported by a grant from the $\mathrm{NIH}$ (R01MH065961) to SM. The authors would like to thank April Qian assisting with data collection.

\section{References}

[1] Amaral DG, Witter MP. The three-dimensional organization of the hippocampal formation: a review of anatomical data. Neuroscience 1989;31:571-91.

[2] Antoniadis EA, McDonald RJ. Fornix, medial prefrontal cortex, nucleus accumbens, and mediodorsal thalamic nucleus: roles in a fear-based context discrimination task. Neurobiol Learn Mem 2006;85:71-85.

[3] Bannerman DM, Yee BK, Lemaire M, Jarrard L, Iversen SD, Rawlins JNP, et al. Contextual fear conditioning is disrupted by lesions of the subcortical, but not entorhinal, connections to the hippocampus. Exp Brain Res 2001;141:30411 .

[4] Bannerman DM, Yee BK, Lemaire M, Wilbrecht L, Jarrard L, Iversen SD, et al. The role of the entorhinal cortex in two forms of spatial learning and memory. Exp Brain Res 2001;141:281-303.

[5] Bouton ME, Westbrook RF, Corcoran KA, Maren S. Contextual and temporal modulation of extinction: behavioral and biological mechanisms. Biol Psychiatry 2006;60:352-60.

[6] Bucci DJ, Phillips RG, Burwell RD. Contributions of postrhinal and perirhinal cortex to contextual information processing. Behav Neurosci 2000;114:882-94. 
[7] Buckley MJ, Charles DP, Browning PG, Gaffan D. Learning and retrieval of concurrently presented spatial discrimination tasks: role of the fornix. Behav Neurosci 2004; $118: 138-49$.

[8] Corcoran KA, Desmond TJ, Frey KA, Maren S. Hippocampal inactivation disrupts the acquisition and contextual encoding of fear extinction. J Neurosci 2005;25:8978-87.

[9] Corcoran KA, Maren S. Factors regulating the effects of hippocampa inactivation on renewal of conditional fear after extinction. Learn Mem 2004; $11: 598-603$.

[10] Corcoran KA, Maren S. Hippocampal inactivation disrupts contextual retrieval of fear memory after extinction. J Neurosci 2001;21:1720-6.

[11] Corcoran KA, Quirk GJ. Recalling safety: cooperative functions of the ven tromedial prefrontal cortex and the hippocampus in extinction. CNS Spectr 2007;12:200-6.

[12] Eacott MJ, Gaffan EA. The roles of perirhinal cortex, postrhinal cortex, and the fornix in memory for objects, contexts, and events in the rat. QJ Exp Psychol B 2005;58:202-17.

[13] Eacott MJ, Norman G. Integrated memory for object, place, and context in rats: a possible model of episodic-like memory? J Neurosci 2004;24:1948-53.

[14] Ennaceur A, Meliani K. A new one-trial test for neurobiological studies of memory in rats. iii. Spatial vs. non-spatial working memory. Behav Brain Res 1992;51:83-92.

[15] Ennaceur A, Neave N, Aggleton JP. Spontaneous object recognition and object location memory in rats: the effects of lesions in the cingulate cortices, the medial prefrontal cortex, the cingulum bundle and the fornix. Exp Brain Res 1997;113:509-19.

[16] Frankland PW, Cestari V, Filipkowski RK, McDonald RJ, Silva AJ. The dorsal hippocampus is essential for context discrimination but not for contextual conditioning. Behav Neurosci 1998;112:863-74.

[17] Frohardt RJ, Guarraci FA, Bouton ME. The effects of neurotoxic hippocampal lesions on two effects of context after fear extinction. Behav Neurosci 2000;114:227-40.

[18] Fyhn M, Molden S, Witter MP, Moser EI, Moser MB. Spatial representation in the entorhinal cortex. Science 2004;305:1258-64.

[19] Gaffan D, Harrison S. Place memory and scene memory: effects of fornix transection in the monkey. Exp Brain Res 1989;74:202-12.

[20] Good M, Honey RC. Conditioning and contextual retrieval in hippocampal rats. Behav Neurosci 1991;105:499-509.

[21] Hargreaves EL, Rao G, Lee I, Knierim JJ. Major dissociation between medial and lateral entorhinal input to dorsal hippocampus. Science 2005;308:1792-4.

[22] Hasselmo ME, Eichenbaum H. Hippocampal mechanisms for the contextdependent retrieval of episodes. Neural Netw 2005;18:1172-90.

[23] Hobin JA, Goosens KA, Maren S. Context-dependent neuronal activity in the lateral amygdala represents fear memories after extinction. J Neurosci 2003;23:8410-6.

[24] Hobin JA, Ji J, Maren S. Ventral hippocampal muscimol disrupts context-specific fear memory retrieval after extinction in rats. Hippocampus 2006;16:174-82.

[25] Holt W, Maren S. Muscimol inactivation of the dorsal hippocampus impairs contextual retrieval of fear memory. J Neurosci 1999;19:9054-62.

[26] Honey RC, Good M. Selective hippocampal lesions abolish the contextual specificity of latent inhibition and conditioning. Behav Neurosci 1993;107: 23-33.

[27] Howard MW, Fotedar MS, Datey AV, Hasselmo ME. The temporal context model in spatial navigation and relational learning: toward a common explanation of medial temporal lobe function across domains. Psychol Rev 2005;112:75116

[28] Ji J, Maren S. Differential roles for hippocampal areas ca1 and ca3 in the contextual encoding and retrieval of extinguished fear. Learn Mem 2008;15:244-51.

[29] Ji J, Maren S. Electrolytic lesions of the dorsal hippocampus disrupt renewal of conditional fear after extinction. Learn Mem 2005;12:270-6.

[30] Ji J, Maren S. Hippocampal involvement in contextual modulation of fear extinction. Hippocampus 2007;17:749-58.
[31] Kennedy PJ, Shapiro ML. Retrieving memories via internal context requires the hippocampus. J Neurosci 2004;24:6979-85.

[32] Kim JJ, Fanselow MS. Modality-specific retrograde amnesia of fear. Science 1992;256:675-7.

[33] Lavenex P, Amaral DG. Hippocampal-neocortical interaction: a hierarchy of associativity. Hippocampus 2000;10:420-30.

[34] Majchrzak M, Ferry B, Marchand AR, Herbeaux K, Seillier A, Barbelivien A Entorhinal cortex lesions disrupt fear conditioning to background context but spare fear conditioning to a tone in the rat. Hippocampus 2006;16:114-24.

[35] Maren S. Building and burying fear memories in the brain. Neuroscientist 2005;11:89-99.

[36] Maren S. Overtraining does not mitigate contextual fear conditioning deficits produced by neurotoxic lesions of the basolateral amygdala. J Neurosc 1998; 18:3088-97.

[37] Maren S, Aharonov G, Fanselow MS. Neurotoxic lesions of the dorsal hippocampus and pavlovian fear conditioning in rats. Behav Brain Res 1997:88:261-74.

[38] Maren S, Fanselow MS. Electrolytic lesions of the fimbria/fornix, dorsal hippocampus, or entorhinal cortex produce anterograde deficits in contextual fear conditioning in rats. Neurobiol Learn Mem 1997;67:142-9.

[39] Maren S, Fanselow MS. Synaptic plasticity in the basolateral amygdala induced by hippocampal formation stimulation in vivo. J Neurosci 1995;15:7548-64.

[40] Maren S, Holt W. The hippocampus and contextual memory retrieval in pavlovian conditioning. Behav Brain Res 2000;110:97-108.

[41] Maren S, Holt WG. Hippocampus and pavlovian fear conditioning in rats: muscimol infusions into the ventral, but not dorsal, hippocampus impair the acquisition of conditional freezing to an auditory conditional stimulus. Behav Neurosci 2004;118:97-110.

[42] Maren S, Quirk GJ. Neuronal signalling of fear memory. Nat Rev Neurosc 2004; 5:844-52.

[43] Markowska AL, Olton DS, Murray EA, Gaffan D. A comparative analysis of the role of fornix and cingulate cortex in memory: rats. Exp Brain Res 1989;74:187-201.

[44] Murray EA, Davidson M, Gaffan D, Olton DS, Suomi S. Effects of fornix transection and cingulate cortical ablation on spatial memory in rhesus monkeys. Exp Brain Res 1989;74:173-86.

[45] Norman G, Eacott MJ. Dissociable effects of lesions to the perirhinal cortex and the postrhinal cortex on memory for context and objects in rats. Behav Neurosci 2005;119:557-66.

[46] O'Reilly RC, Rudy JW. Conjunctive representations in learning and memory: principles of cortical and hippocampal function. Psychol Rev 2001;108:311-45.

[47] Pavlov IP. Conditioned reflexes: an investigation of the physiological activity of the cerebral cortex. London: Oxford University Press; 1927.

[48] Phillips RG, LeDoux JE. Differential contribution of amygdala and hippocampus to cued and contextual fear conditioning. Behav Neurosci 1992;106:274-85.

[49] Phillips RG, LeDoux JE. Lesions of the fornix but not the entorhinal or perirhinal cortex interfere with contextual fear conditioning. J Neurosci 1995;15:5308-15.

[50] Scharfman HE, Witter MP, Schwarcz R. The parahippocampal region: implications for neurological and psychiatric diseases. Introduction. Ann N Y Acad Sci 2000;911, ix-xiii.

[51] Steffenach HA, Witter M, Moser MB, Moser EI. Spatial memory in the rat requires the dorsolateral band of the entorhinal cortex. Neuron 2005;45:301-13.

[52] Swanson LW, Cowan WM. An autoradiographic study of the organization of the hippocampal formation in the rat. J Comp Neurol 1977:49-84.

[53] Ueki A, Miwa C, Miyoshi K. Impairment in the acquisition of passive and active avoidance learning tasks due to bilateral entorhinal cortex lesions. J Neurol Sci 1994; $125: 14-21$.

[54] Wilson A, Brooks DC, Bouton ME. The role of the rat hippocampal system in several effects of context in extinction. Behav Neurosci 1995;109:828-36.

[55] Wood ER, Dudchenko PA, Robitsek RJ, Eichenbaum H. Hippocampal neurons encode information about different types of memory episodes occurring in the same location. Neuron 2000;27:623-33. 